\title{
Cap. 24. CARACTERISTICILE SPIRITULUI ANTREPRENORIAL DIN ROMÂNIA
}

\author{
Lorena Florentina Dumitrașciuc \\ Alexandru Ioan Cuza University, Iași, Romania, Doctoral School of Economics and Business \\ Administration, lorena.popescul@gmail.com
}

\begin{abstract}
:
Purpose: The purpose of this research is to analyze the characteristics of entrepreneurship in influential people in Romania, given that entrepreneurship is what guarantees the success of any business.

Methodology: There are five indicators that show that a certain person has the entrepreneurial spirit: passion, optimism, continuous improvement, take calculated risks and achieve their goals.

Results: Entrepreneurship is not learned, but is formed over time and is formed from within the person. So entrepreneurship becomes part of what people really are. Entrepreneurship develops in people, when they feel motivated, empowered, take risks, show passion and are willing to achieve great goals. In other words, to exceed their own limits. Also, the entrepreneurial spirit is always looking for change, because here it is a mentality that is constantly looking for innovation, in seeing the big picture, always looking for constructive feedback, always looking for new opportunities and in to always have a critical spirit. In addition, due to the entrepreneurial spirit that a person manifests, their employees will embrace this entrepreneurial mentality and will come up with new ideas, solutions and opportunities to problems, and this makes organizations grow and develop.
\end{abstract}

Key words: entrepreneurship, entrepreneurship spirit, passion, achieving goals.

\section{Introducere}

În ziua de astăzi, afacerile trebuie să țină pasul cu schimbările, astfel că este nevoie de creativitate atât la nivel strategic, cât și la nivelul schimbărilor impuse de către concurență (Gries, 2011).

În ceea ce-i privește pe antreprenori, aceștia trebuie să lideri autentici și să nu se teamă să fie altfel în fața celorlalți. Liderii trebuie în primul rând să învețe să fie membri ai echipei și să înţeleagă faptul că echipa lor are idei valoroase (Kiyosaki, 2011).

De asemenea, aceștia trebuie să fie agili (flexibili), să aibă capacitatea de a se schimba, de a inova, de a renunța la propriile programe și scopuri, având în vedere împrejurările incerte și viteza cu care survine schimbarea în lumea de astăzi (Whitmore, 2014).

Spiritul antreprenorial este necesar în vederea creșterii productivității afacerilor pe termen lung, ceea ce îi determină pe antreprenori să caute noi modalități de a produce bunuri și de a identifica resurse pentru a satisface nevoile piețelor (Shepherd și Douglas, 1997).

Este necesar ca spiritul antreprenorial să se dezvolte mai mult în România, pentru că antreprenorii sunt cei care contribuie la schimbarea lumii, prin afacerile lor și prin impactul lor social și economic (Davis, 2002).

Astfel că spiritul antreprenorial este cel care îi motivează pe oameni să intre în afaceri, să persiste și să aibă succes (Bird, 1989).

În plus, antreprenoriatul reprezintă o atitudine și nu este un loc de muncă (Nobre, 2002).

\section{Spiritul antreprenorial - Literature Review}

Antreprenoriatul este cel care arată calea de urmat către gestionarea organizațională şi dezvoltarea personală în noua economie și oferă totodată un impuls în vederea dezvoltării economice (Matlay și Mitra, J. (2002). 
Spiritul antreprenorial se referă la capacitatea indivizilor de a vedea oportunități acolo unde alții văd probleme și de a acționa în vederea rezolvării problemelor, cu scopul realizării de profit (Eckhardt și Shane, 2003, Mueller, 2007).

Totodată, spiritul antreprenorial este marcat de perseverență, iniţiativă, determinare, imaginație, disponibilitatea de a dezvolta noi proiecte, asumarea de riscuri (Tan et al., 1995), curaj, onestitate, integritate și încredere, deoarece acesta are un rol semnificativ în ceea ce privește învățarea de noi abilități (Molden, 2013).

Persoanele cu spirit antreprenorial au dorința de a valorifica oportunitățile, prin realizarea de activități care conduc către crearea averii și la valoare adăugată (Ang și Hong, 2000).

Antreprenorii sunt lideri, ceea ce înseamnă că echipa îl determină pe antreprenor să devină mai puternic, să își întărească punctele tari și să își compenseze punctele slabe (Kiyosaki, 2011).

Indivizii cu spirit antreprenorial sunt cei care învață mai mult spre deosebire de cei din propriul anturaj, deoarece cu cât aceștia învață mai mult și mai repede, cu atât mai uşor se pot adapta și evolua. În plus, astfel de persoane au abilitatea de a testa mai multe lucruri, spre deosebire de oamenii din jurul lor pentru a atinge succesul (Parra, 2013).

De asemenea, în contextul antreprenoriatului se pot aborda în mod eficient inovarea, învăţarea, precum și gestionarea de cunoștințe (Matlay și Mitra, 2002).

Referitor la persoanele ce dețin spiritul antreprenorial, acestea au obiceiul de a persevera în vederea atingerii scopului dorit, spre deosebire de alți oameni din jurul lor (Vuong, 2016). În momentul în care oamenii perseverează, fără să mai țină cont de obstacolele temporare, aceștia se diferențiază destul de mult de majoritatea oamenilor. Ceea ce înseamnă că nivelurile ridicate de perseverență și autoeficiență îi ajută pe antreprenori să depăşească neplăcerile și obstacolele (Markman, Baron și Balkin, 2004).

Indivizii cu spirit antreprenorial și-au ales mediul în care să acționeze, și-au găsit identitatea, și-au stabilit setul de valori și convingeri, au încredere în cunoștințele și abilitățile lor, au un anumit comportament ce le permite să gândescă la nivel înalt, ceea ce contribuie la crearea nivelurilor de învățare, comunicare și transformare a antreprenorilor (Molden, 2013).

În plus, antreprenorii care își înțeleg propriile valori și pe cele ale altor persoane, ar putea înțelege mai bine schimbările pieței către sustenabilitate (Parra, 2013).

Şi nu în cele din urmă, persoanele cu spirit antreprenorial sunt motivate să caute diferite soluții la probleme și să își asume riscuri (Markman, Baron și Balkin, 2004, Van Gelderen, 2012).

În ceea ce privește riscul, acesta este periculos numai în cazul oamenilor care se complac în propriile lor situații și în condițiile în care nu caută alternative la propriile probleme.

În schimb, antreprenorii care își asumă riscuri au şi o atitudine corespunzătoare, faţă de cei care nu își asumă riscuri. Și anume aceea de a căuta mereu noi soluții. (Kiyosaki, 2014).

Pornind de la aceste considerente, vrem să aflăm care sunt caracteristicile spiritului antreprenorial din România.

\section{Metodologie}

Scopul acestei cercetări este de a analiza care sunt caracteristicile spiritului antreprenorial la oamenii cu influență din România, având în vedere faptul că spiritul antreprenorial este cel care garantează succesul oricărei afaceri.

Există cinci indicatori sugerați de literatura de specialitate, care demonstrează că o anumită persoană deține spiritul antreprenorial, printre care avem: pasiune (Biraglia, et al., 2016, Cardon et al. 2017, Cardon, 2013, Cardon, 2005 și Warnick, et. Al, 2018), optimism (Bernoster, et al., 2018, Popescul, 2017, Dawson, et al. 2014, Hyytinen, et al., 2012 și Storey, 2011, Crane şi Crane, 2007), îmbunătăţire continuă (Winkler, et al. 2018 și Popescul, 2017), asumarea riscurilor calculate (Cardon et al. 2017 și Maxwell, 2008) și atingerea obiectivelor propuse (Popescul, 2017 și Samwel, 2010).

Indicatorii sunt măsuraţi astfel: 
(1) pasiune - antreprenorilor le place ceea ce fac, vocație;

(2) optimism - utilizarea cuvintelor cu conotații pozitive, dezvoltare pe plan personal și profesional;

(3) îmbunătăţire continuă - dobândirea de abilităţi noi, creativitate;

(4) antreprenorii își asumă riscuri calculate - antreprenorii cunosc momentul oportun când să facă noi investiții sau schimbări strategice

(5) antreprenorii își ating obiectivele propuse - dacă antreprenorii au reușit să ducă la îndeplinire ceea ce și-au propus.

\section{Rezultate și discuții}

Scopul acestei cercetări este de a analiza care sunt caracteristicile spiritului antreprenorial.

Am observat că un rol important îl au atitudinea și factorii înconjurători, cum ar fi de exemplu, ideea că aceștia au crescut într-un mediu în care s-a discutat și s-au făcut afaceri sau au căutat ca aceștia să facă parte dintr-un astfel de mediu, dorind să iasă din mulțime și să vadă și să facă lucrurile în mod diferit, spre deosebire de cei din jurul lor.

De exemplu, în studiul realizat de Kirkwood (2007), s-a constatat faptul că cei care îi pot ajuta pe tineri în primă fază sunt părinţii, care ar trebui să fie mult mai atenţi la ce îşi doreşte cu adevărat copilul lor, să îi descopere înclinaţiile şi să îi dezvolte punctele forte. Iar cei care joacă rolul principal în decizia de creare a riscului sunt tații.

În cazul părinților cu afaceri, femeilor antreprenoare au primit sfaturi, sprijin și încurajare din partea părinților, în timp ce bărbații antreprenori au dorit să fie independenți precum părinții lor (orientându-se după tați în special) sau au încercat să concureze cu ei (Kirkwood, 2007).

În urma analizei, am observat faptul că au existat și oameni care nu au avut parte de un mediu de afaceri familial, însă au avut atitudinea de învingători, s-au pregătit pentru ceea ce urmau să devină, şi-au stabilit obiective, și-au asumat riscuri, au depus un efort semnificativ de învățare și adaptare, astfel că aceștia au demonstrat că se poate să devii antreprenor și fără să fii crescut întrun mediu de afaceri familial.

În ceea ce privește succesul antreprenorilor, acesta depinde foarte mult de calitatea echipei pe care aceștia și-o formează (Kiyosaki, 2011).

Însă, pentru a-şi putea proiecta succesul, antreprenorii trebuie să-şi stabilească obiective (Popescul, 2017). Ideea este să persevereze, să testeze ideile și să aibă modele și mentorii potriviți de la care să învețe (Molden, 2013).

De asemenea, am constatat în urma analizei că spiritul antreprenorial se dezvoltă la oameni în momentul în care aceștia se simt motivați, împuterniciți, își asumă riscuri, își manifestă pasiunea și sunt dispuşi să își atingă obiective mari. $\mathrm{Cu}$ alte cuvinte, să își depășească propriile limite.

Pentru că există antreprenori care identifică o problemă şi găsesc imediat o oportunitate de afacere. Astfel că optimismul este o caracteristică dominantă a antreprenorilor (Cassar, 2010). De asemenea, s-a constatat că optimismul este mai ridicat, atunci când un individ lucrează pe cont propriu (Dawson, 2014). Astfel că munca independentă atrage optimismul intrinsec (Dawson, 2014).

Așadar, antreprenorii își transformă problemele în oportunități (Keller, 2012).

Din analiza poveștilor de viață ale acestora, am remarcat faptul că toate aceste persoane care şi-au deschis afaceri și au devenit antreprenori de succes, au dezvoltat anumite pasiuni pentru ideile lor. Astfel că succesul antreprenorial se datorează combinaţiei între viziune (Whitmore, 2014), pasiune, planificare, perseverență, muncă, investiţii, viteza cu care înaintează, învingerea obstacolelor și contextul favorabil.

O altă observație pe care am remarcat-o în timpul studiului antreprenorilor, este aceea că persoanele cu spirit antreprenorial își asumă riscuri și gândesc la scară mare. Aceștia învaţă în mod continuu şi caută noi modalități de a-și îmbunătăţi abilită̌ţile existente pentru a progresa. 
În plus, antreprenorii și-au folosit pasiunea pentru crearea și creșterea de noi riscuri (Cardon, 2005), care să îi ajute să se dezvolte la scară largă.

În analiză am identificat antreprenori care au dezvoltat succesul din eșecuri. Pentru a ajunge la succes, de cele mai multe ori antreprenorii sunt descurajați și au de înfruntat eșecul. Însă, antreprenorii au privit fiecare provocare ca pe o oportunitate.

Totodată, aceștia au avut curaj și au fost capabili să înfrunte eșecul și să învețe din el, pentru a atinge culmile succesului. Mai ales că mereu oamenii au admirat curajul, indiferent de mediul din care aparțin (Carnegie, 2008).

Pornind de la analiza literaturii de specialitate am creat un model al spiritului antreprenorial (ESM - entrepreneurial spirit model), care cuprinde:

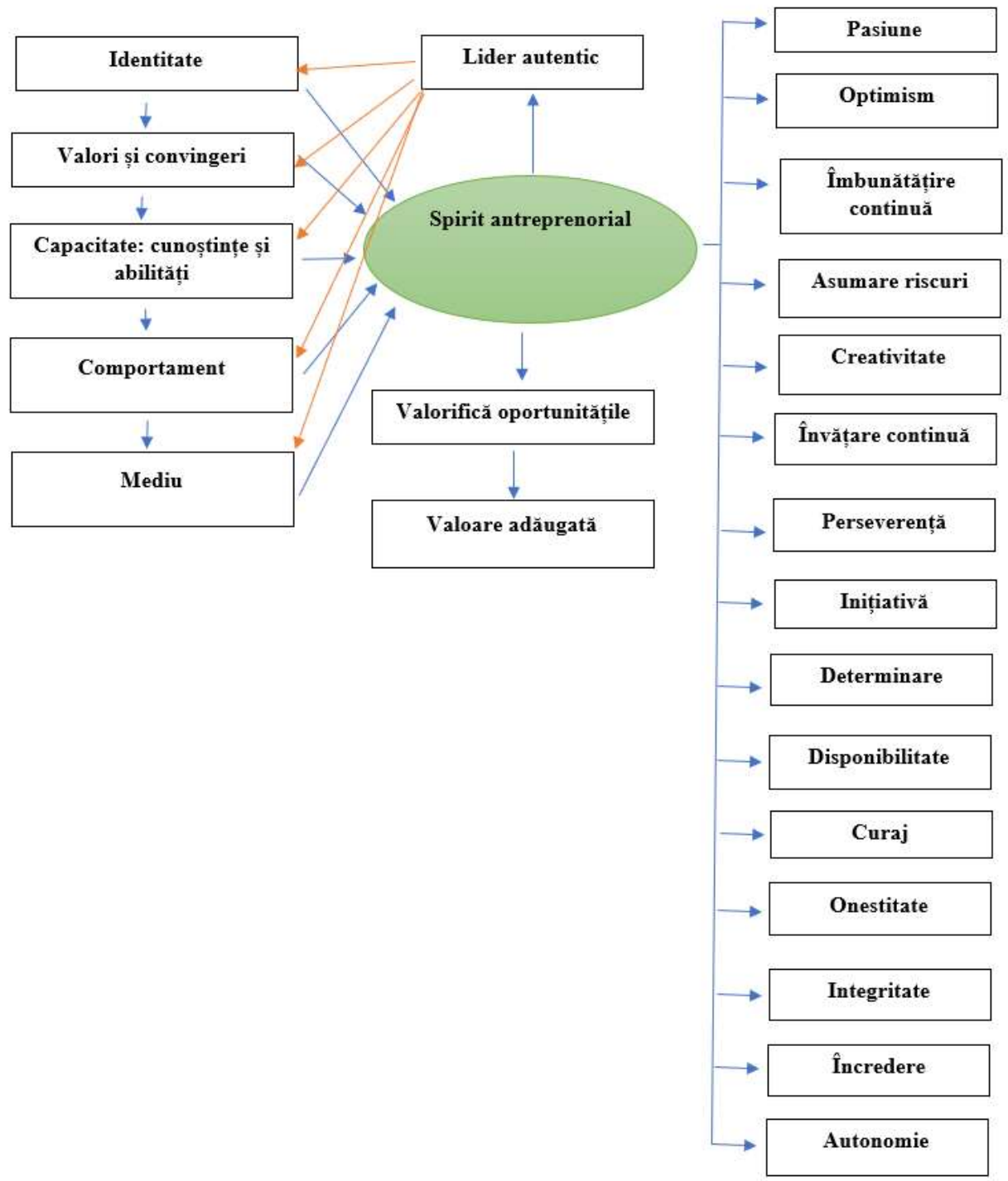

Fig. 1. Modelul ESM - entrepreneurial spirit model 
Afacerile de succes sunt cele care au luat naștere din pasiuni. De exemplu, în studiul realizat de Cardon (2005), s-a constatat faptul că pasiunea antreprenorială este o metaexperiență emoțională, care influențează trei factori cheie ai eficienței antreprenoriale, cum ar fi de pildă: perseverența, rezolvarea problemelor și concentrarea. Astfel că atât experiențele emoționale subconștiente, cât și cele cognitive sunt influențate de către acești factori cheie.

Referitor la optimism, acesta se dobândește prin învățare socială, astfel că antreprenorii de succes trebuie să devină modele extrem de vizibile, învățând și încurajând pe alții să intre în domeniul antreprenorial (Crane și Crane, 2007).

În studiul lui Dawson (2014) s-a constatat că cei care vor deveni proprii angajaţi sunt mai optimiști, spre deosebire de angajații care nu vor lucra niciodată pentru ei înșişi. Angajații care aspiră la activități independente, își supraestimează randamentul mai mult decât cei care nu au astfel de aspirații.

În momentul în care antreprenorii se gândesc încontinuu la scopul pe care și-l doresc să şi-l atingă, își vor îndrepta paşii către atingerea scopului (Keller, 2012).

Referitor la partea de îmbunătăţire continuă, antreprenorii de succes sunt cei care iau iniţiative şi care au un nivel ridicat de creativitate. Totodată, antreprenorii își pot folosi creativitatea, pentru a căuta soluții la problemele sociale și de mediu, legate de viitoarea lor organizație (Parra, 2013).

În studiul realizat de Ang și Hong (2000), intitulat "Entrepreneurial spirit among East Asian Chinese", a reieșit faptul că spiritul antreprenorial în rândul tinerilor chinezi din Asia de Est este prezis de caracteristicile personalității, cum ar fi propensiunea asumării riscurilor, persistența și locusul intern al controlului, precum și de factori motivaționali, bani și dorința de securitate.

Spiritul antreprenorial se află mereu în căutarea schimbării, pentru că aici este vorba despre o mentalitate care se află în permanență în căutarea inovării, în a vedea imaginea de ansamblu, a căuta mereu feedback constructiv, în a căuta mereu noi oportunități și în a avea mereu spiritul critic. De asemenea, aceștia ar trebui să își schimbe obiectivele, pentru a obține noi comportamente și rezultate noi sustenabile (Parra, 2013).

În plus, datorită spiritului antreprenorial pe care o persoană îl manifestă, angajații acestora vor îmbrățișa această mentalitate antreprenorială și vor ajunge să vină cu noi idei, soluții și oportunități la probleme, iar acest lucru face ca organizațiile să crească și să se dezvolte.

\section{Concluzii}

Pasiunea trebuie să pornească de la vocaţie, de la a-şi defini ceea le face plăcere să facă, întrucât pasiunea este inima antreprenoriatului (Cardon, et al., 2013).

Această lucrare a arătat faptul că optimismul este o trăsătură care predispune indivizii la angajarea pe cont propriu sau reprezintă o creație a entuziasmului și a intensității care este de obicei implicat în aventura unei afaceri (Dawson, 2014).

Ideea este ca doza de optimism să fie în limitele normale, pentru că atunci când este exagerat poate afecta rentabilitatea profesională, ceea ce îi poate determina pe lucrătorii independenți să revină la angajarea remunerată (Dawson, 2014). Iar o doză prea mare de optimism poate duce la așteptări financiare greșite (Dawson, 2014).

În ceea ce privește partea de îmbunătățire continuă, este imperios necesară educaţia în domeniul antreprenorial în rândul tinerilor încă din școli, pentru că odată ajunși la maturitate, mentalitatea acestora se va schimba.

În felul acesta, tinerii vor învăța cum să iși rezolve problemele, cum să-i conducă pe alții, cum să pună întrebări, să facă bani, cum să vândă, să vorbească în public, să învețe din greșeli, să știe să ceară ajutorul, să fie creativi, să aleagă soluțiile cele mai bune și să învețe să economisească. 
Într-un final, tinerii ajunși la maturitate vor căuta să fie independenți și să aibă propriile lor afaceri de succes.

Practic, spiritul antreprenorial îi va putea ajuta pe tineri să ia viaţa în propriile mâini şi să contribuie la schimbarea lumii.

În România este nevoie de o generaţie de lideri care să-şi asume riscuri, să dea dovadă de creativitate, energie, să fie optimiști, orientați către atingerea obiectivelor și spre rezultate.

În momentul în care antreprenorii își asumă riscuri, aceștia ies din zona de confort, pentru că riscurile presupun de regulă anumite neplăceri sau neajunsuri pentru antreprenori. Fiecare antreprenor are anumite temeri în materie de riscuri, însă tocmai aceste temeri îi determină pe aceștia să conștientizeze ce s-ar putea întâmpla în viitor și s-ar putea să nu întâmpine neplăceri, în condițiile în care vor învăța să se asculte (Semenik, 2016).

Antreprenorii ajung să ị̂si atingă obiectivele, în momentul în care aceștia au o echipă de experți din fiecare domeniu de activitate (Kiyosaki, 2011).

Apoi, am arătat faptul că nimeni nu se naște cu spiritul antreprenorial, ci acesta se cultivă. Iar un rol important îl au atitudinea și factorii înconjurători, cum ar fi de exemplu ideea că aceștia au crescut într-un mediu în care s-a discutat și s-au făcut afaceri.

Antreprenorii pot apela la sesiuni de life coaching, pentru că acestea contribuie la îmbunătățirea relațiilor cu ceilalți, îi ajută pe antreprenori să iși stabilească obiectivele SMART și să își crească performanța.

În acest studiu, am arătat că există situații în care oamenii nu au avut parte de un mediu de afaceri familial şi cu toate acestea au demonstrat că se poate şi fără.

La final, am creat un model al spiritului antreprenorial (ESM - entrepreneurial spirit model), care poate fi utilizat de antreprenori, pentru a-și îmbunătăți abilitățile și competențele, cât și pentru coach-ii care doresc să faciliteze creșterea și dezvoltarea anumitor aspecte ale afacerii.

De asemenea, remarcăm faptul că în cazul antreprenorilor este foarte important mediul în care trăiesc, pentru că mediul determină informația pe care oamenii o primesc, cu ajutorul celor cinci simţuri: vizual, auditiv, tactil, olfactiv și gustativ (Molden, 2013).

\section{Acknowledgement}

This work was co-funded by the European Social Fund, through Operational Programme Human Capital 2014-2020, project number POCU/380/6/13/123623, project title $<<\mathrm{PhD} \mathrm{Students}$ and Postdoctoral Researchers Prepared for the Labour Market!>>.

\section{Bibliografie}

- Ang, S.H., Hong, D.G.P. (2000). Entrepreneurial spirit among East Asian Chinese. Thunderbird International Business Review 42(3), 285-309.

- Bernoster, I., Rietveld, C., Thurik, A., Torrès, O. (2018). Overconfidence, Optimism and Entrepreneurship. Sustainability 10(7).

- Biraglia, A., Kadile, V., 2016. The Role of Entrepreneurial Passion and Creativity in Developing Entrepreneurial Intentions: Insights from American Homebrewers. Journal of Small Business Management 55(1), 1-19.

- Bird, B.J. (1989). Entrepreneurial behavior. London, U.K.: Scott, Foresman, and Co.

- Cardon, M.S., Glauserb, M., Murnieksc, C.Y. (2017). Passion for what? Expanding the domains of entrepreneurial passion. Journal of Business Venturing Insights 8, 24-32.

- Cardon, M.S., Post, C., Forster, W., 2017. Team entrepreneurial passion: its emergence and influence in new venture teams. Academy of Management Review 42(2).

- Cardon, M.S., Gregoire, D.A., Stevens, C.E., Patel, P.C. (2013). Measuring entrepreneurial passion: Conceptual foundations and scale validation. Journal of Business Venturing 28(3), 373-396. 
- Cardon, M.S., Wincent, J., Singh, J., Drnovsek, M. (2005). Entrepreneurial passion: the nature of emotions in entrepreneurship. Academy of Management Proceedings (1).

- Carnegie, D. (2008). Cum să vorbim în public. Editura Curtea Veche, București, p.16.

- Cassar G. (2010). Are individuals entering self-employment overly optimistic? An empirical test of plans and projections on nascent entrepreneur expectations. Strategic Management Journal 31(8), 822-840.

- Crane, F.G., Crane, E.C. (2007). Dispositional optimism and entrepreneurial success. The Psychologist-Manager Journal 10(1), 13-25.

- Davis, S.M. (2002). Social Entrepreneurship: Towards an Entrepreneurial Culture for Social and Economic Development. SSRN Electronic Journal.

- Dawson, C., de Meza, D., Henley, A., Arabsheibani, G.R. (2014). Entrepreneurship: Cause and Consequence of Financial Optimism. Journal of Economics \& Management Strategy 23(4), 717-742.

- Eckhardt, J.T., Shane, S.A. (2003). Opportunities and Entrepreneurship. Journal of Management 29(3).

- Flaherty, J. (1999). Coaching: Evoking excellence in others. Burlington, MA: Elsevier.

- Galor, O., Michalopoulos, S. (2007). The Evolution of Entrepreneurial Spirit and the Process of Development. CEPR Discussion Paper No. 6022.

- Gries, T., Naude, W. (2011). Entrepreneurship, Structural Change and a Global Economic Crisis. Entrepreneurship Research Journal 1(3).

- Hyytinen, A., Lahtonen, J., Pajarinen, M. (2012). Entrepreneurial Optimism and Survival, Bank of Finland Research Discussion Paper No. 20.

- Keller, J. (2012). Atitudinea este totul. Schimbă-ți atitudinea ... și îți vei schimba viața!. Editura Curtea Veche, București, 32.

- Kirkwood, J. (2007). Igniting the entrepreneurial spirit: is the role parents play gendered?. International Journal of Entrepreneurial Behavior \& Research 13(1).

- Kiyosaki, R. (2014). Avantajul inechitabil: puterea educației financiare. Editura Curtea Veche, București, 11.

- Markman, Baron, R.A., Balkin, D.B. (2004). Are perseverance and self-efficacy costless? Assessing entrepreneurs' regretful thinking. Journal of Organizational Behavior 26(1), 1-19.

- Matlay, H., Mitra, J. (2002). Entrepreneurship and Learning: The Double Act in the Triple Helix. The International Journal of Entrepreneurship and Innovation 3(1), 7-16.

- Maxwell, J., 2008. Talentul nu este suficient. București, Editura Amaltea.

- Molden, D. (2013). Management cu NLP. Editura Curtea Veche, București.

- Mueller, P. (2007). Exploiting Entrepreneurial Opportunities: The Impact of Entrepreneurship on Growth. Small Business Economics 28(4), 355-362.

- Nobre, A.L. (2002). Entrepreneurship as an Attitude. The International Journal of Entrepreneurship and Innovation 3(1), 17-25.

- Parra, S. (2013). Exploring the Incorporation of Values for Sustainable Entrepreneurship Teaching/Learning. Journal of Technology Management \& Innovation 8(1), 11-20.

- Popescul, L.F. (2017). The Impact of Life Coaching Sessions on the Behavior of Future Romanian Entrepreneurs - Pilot Study. "Ovidius" University Annals, Economic Sciences Series, 17(2), 449-454.

- Popescul, L.F. (2017). The influence of life coaching sessions on the entrepreneurs' behavior. Journal of Public Administration, Finance and Law, 12, 137. 
- Samwel Mwasalwiba, E. (2010). Entrepreneurship education: a review of its objectives, teaching methods, and impact indicators. Education + Training 52(1), 20-47.

- Semenik, D. (2016). Cum să biruim frica. Editura Sophia, București, 51-52.

- Sexton, D.L., Bowman-Upton, N. (1991). Entrepreneurship: creativity and growth. Macmillan.

- Shepherd, D.A., Douglas, E.J. (1997). Is Management Education Developing, or Killing, the Entrepreneurial Spirit?. USASBE Annual National, Centre for Entrepreneurial Studies, School of Business, Bond University, Gold Coast, Australia 4229.

- Storey, D.J. (2011). Optimism and chance: The elephants in the entrepreneurship room. International Small Business Journal 29(4), 303-321.

- $\quad$ Tan, W.L., Siew, L.K., Tan, W.H., Wong, S.C. (1995). Entrepreneurial spirit among tertiary students in Singapore. Journal of Enterprising Culture 3(2), 211-227.

- Van Gelderen, M. (2012). Perseverance strategies of enterprising individuals. International Journal of Entrepreneurial Behavior \& Research 18(6), 630-648.

- Vuong, Q.H. (2016). Impacts of geographical locations and sociocultural traits on the Vietnamese entrepreneurship.

- Warnick, B.J., Murnieks, C.Y., McMullen, J.S., Brooks, W.T. (2018). Passion for entrepreneurship or passion for the product? A conjoint analysis of angel and $\mathrm{VC}$ decisionmaking. Journal of Business Venturing 33(3), 315-332.

- Whitmore, S.J. (2014). Coaching pentru performanță. Editura Publica, București.

- Winkler, C., Saltzman, E., Yang, S. (2018). Improvement of Practice in Entrepreneurship Education Through Action Research: The Case of Coworking at a Nonresidential College. Entrepreneurship Education and Pedagogy 1(2), 139-165. 